\title{
A TRADUÇÃO DE CONTOS DE JuANa MaNuEla GorRiti PARA O PORTUGUÊS BRASILEIRO
}

\section{Artur Emilio Alarcon Vaz* Daniele Corbetta Piletti** Joselma Maria Noal***}

Resumo: O presente artigo visa compartilhar os resultados do projeto de pesquisa "Juana Manuela Gorriti: análise e tradução". Desenvolvido com graduandos do curso de Letras Português/Espanhol, na Universidade Federal do Rio Grande (Furg), esse projeto tem o objetivo de traduzir a obra de Juana Manuela Gorriti para o português brasileiro e de melhorar o conhecimento de língua espanhola dos acadêmicos envolvidos. A análise fundamenta-se nos Estudos Descritivos da Tradução de Gideon Toury (2004), que propõe normas preestabelecidas a serem usadas no ato tradutório.

Palavras-chave: Estudos descritivos da tradução. Tradução literária. Juana Manuela Gorriti.

"E sta proposta fundamenta-se também na necessidade de repensar o espaço dado no Brasil às obras produzidas pela argentina Juana Manuela Gorriti (1816-1892), praticamente desconhecida nos meios literários e acadêmicos brasileiros, já que não há traduções de obras completas para a língua portuguesa, mesmo após mais de um século de sua morte e décadas após seus textos terem entrado em domínio público.

Esse intercâmbio entre os países latino-americanos é extremamente necessário, devido à enorme diferença de status dessa autora no Brasil e em outros países. Embora as obras estejam inseridas entre os clássicos latino-americanos do século XIX e sejam reimpressas até hoje, como na inclusão da obra Dreams

\footnotetext{
* Universidade Federal do Rio Grande (FURG) - Rio Grande - RS - Brasil. E-mail: arturvaz@furg.br

** Universidade Federal do Rio Grande (FURG) - Rio Grande - RS - Brasil. E-mail: danielepiletti@furg.br

*** Universidade Federal do Rio Grande (FURG) - Rio Grande - RS - Brasil. E-mail: joselmanoal@furg.br
} 
and realities (GORRITI, 2003) na Coleção "Biblioteca da América Latina", pela Editora Oxford, seu nome no Brasil é raramente citado entre obras de mulheres que influenciaram na reflexão feminista da América Latina, mesmo entre disciplinas de literatura hispano-americana de universidades brasileiras.

A pouca produção acadêmica no Brasil sobre a obra dessa escritora foi comprovada numa busca nos currículos do sistema Lattes, na qual foram encontrados poucos pesquisadores brasileiros da obra de Juana Manuela Gorriti. Outro indicador é a presença de um único romance dessa autora na Biblioteca Nacional Brasileira. Em comparação, na Biblioteca Nacional da Argentina, há 82 livros com textos de autoria de Gorriti. Igualmente, na Biblioteca Nacional do Chile, há 11 romances e, na Biblioteca Nacional do Peru, 14 obras. Dados como esses demonstram que é possível que, com a tradução de sua obra para o português brasileiro, aumentem também nos sites em língua portuguesa a apresentação e a publicação de artigos, além de dissertações, teses e livros sobre a autora.

Portanto, uma das formas de aproximar a escritora do público leitor brasileiro é a análise, a tradução e a publicação de suas obras. Assim, formou-se uma equipe de alunos, coordenados por duas professoras de língua espanhola com experiência em tradução e um professor de literatura com experiência na análise e recuperação de textos do século XIX, todos vinculados ao Instituto de Letras e Artes.

Conforme Hurtado Albir (2013, p. 63), além do domínio linguístico,

[...] o tradutor literário necessita de competências específicas (uma competência literária): amplos conhecimentos literários e culturais e determinadas aptidões relacionadas com ofuncionamento desses textos (boas habilidades de escrita, criatividade, etc.)"1,

dado que tais competências permitirão a solução de problemas específicos de tradução como questões de estilística (compreensão de metáforas e expressões idiomáticas) e também a intervenção da dimensão diacrônica e o estilo do autor nas relações socioculturais no contexto do Texto de Origem (TO).

Rosemary Arrojo (1996) afirma que não existe nem tradução nem leitura que sejam neutras e que o tradutor é, em certo sentido, um coautor do texto que traduz, fato esse que estabelece uma interseção com as teorias da linguagem que se preocupam com o uso funcional da língua, dado que o tradutor leva em consideração o contexto sociocultural do autor ao escrever o TO e o contexto do público-alvo de sua tradução.

André Lefevere (1985) afirma que toda tradução é uma reescrita e, como tal, implica uma manipulação, pois os tradutores-reescritores manipulam os originais, para fazer com que se ajustem à ideologia e à poética da época do Texto Meta (TM). Sendo assim, adota-se, neste trabalho, o conceito de ideologia do referido autor, que a entende como o entrelaçado de forma, convenção e crenças que ordena as ações do tradutor. Outra estratégia utilizada pelo tradutor, também apontada por Lefevere, é a poética, que preconiza que um tradutor manipula a obra literária até que seja aceitável para a poética de sua obra. Segundo o autor, os componentes que formam a poética são dois: um inventário que abran-

1 Quando não indicada nas referências, a tradução das citações é de nossa autoria. 
ge os recursos literários e outro que guarda relação com influências ideológicas, esse denominado funcional. Isso esclarece que o tradutor deve levar em consideração o universo do leitor do TO e o do TM, pois ambos muitas vezes têm uma grande distância temporal. Isso pode ser exemplificado por meio do projeto desenvolvido, posto que os tradutores devem aproximar o texto escrito pela autora argentina do século XIX do leitor brasileiro do século XXI.

Outro fator que Lefevere (1997) entende que pode ter repercussão na tradução é o universo do discurso, que é um conjunto de conhecimentos, crenças, conceitos e costumes que compõem uma cultura em uma determinada época. $\mathrm{E}$, também, o que intervém na tradução é a linguagem, o modo como se usa e se manipula a língua para conseguir determinados efeitos.

Nesse mesmo sentido, Gideon Toury (1995) apresenta justificativas para a existência de regras, normas e idiossincrasias ao longo do processo tradutório. Entre elas, destaca os diversos tipos textuais ou tipos de público, o que leva o tradutor a adotar diferentes estratégias, daí a necessidade de que a prática tradutora seja pensada mediante normas estabelecidas em consonância com políticas socioculturais específicas e contextos históricos. Toury entende por norma a tradução de ideias e valores gerais compartilhados por uma comunidade em relação com o que está bem ou mal, adequado ou inadequado; além disso, uma norma deve ser aplicável a situações específicas. Dessa forma, trata-se de induções socioculturais específicas de uma cultura e de um período histórico.

A partir do conceito de norma, pode-se diferenciar a regularidade de comportamentos em situações recorrentes. O autor afirma que a norma pode ser aplicada não só em traduções de todo tipo, mas também em todas as etapas do ato tradutório e, consequentemente, em todos os niveis de geração de um produto de tradução. As premissas dos Estudos Descritivos da Tradução de Toury (1980) propõem o reconhecimento da literatura como um sistema cultural que inclui a situação histórica, cultural e social do texto e destaca seu impacto na atividade tradutória.

Cabe destacar ainda que a concepção adotada neste texto sobre a tradutologia, criada por Hurtado Albir (2013), é de que se trata de uma atividade cognitiva, ou seja, não é apenas a decodificação de uma língua a outra, mas também, e principalmente, um ato comunicativo e uma operação textual. Essa premissa justifica o papel didático da tradução no ensino de línguas apresentado neste artigo.

O ensino do espanhol como Língua Adicional (LA), na atualidade, não se restringe somente à abordagem comunicativa, devido a diferentes fatores históricos, sociais e culturais. De acordo com Vilson Leffa e Valesca Irala (2014), o ensino de línguas na contemporaneidade inclui três aspectos que são essenciais: a pedagogia crítica, a questão da LA e a pedagogia de projetos. O ponto de partida é o fato de que é necessário motivar o aluno, realizando atividades interdisciplinares que contemplem as sutis diferenças entre as linguas, nesse caso português e espanhol, evidenciando os aspectos (inter)culturais (LEFFA; IRALA, 2014), que podem ser trabalhados por meio da literatura na sala de aula de lingua.

A crença de que a integração desses aspectos deveria ser tratada como relevante pelo professor de linguas levou-nos a realizar o referido projeto, dado que contribui para a aprendizagem autônoma e que, além de capacitar os envolvidos no domínio linguístico, também contribui para seu enriquecimento cultural, histórico, político e social. Leffa e Irala (2014, p. 275) afirmam que "os aspectos de ordem histórica, geográfica e politica devem, com urgência, fazerem-se mais 
presentes na formação do futuro docente". Os textos literários selecionados para a tradução foram escritos no século XIX e retratam o período político, histórico, social e cultural da Argentina daquele momento, que deve ser entendido pelo leitor brasileiro contemporâneo, tarefa de responsabilidade dos aprendizes, no papel de tradutores literários.

Luis Pegenaute Rodríguez (1996, p. 110), em seu artigo "La traducción como herramienta didáctica", mostra que "el traductor no nace; se hace" e cita que o aluno, ao realizar atividades de tradução em sala de aula, aperfeiçoará tanto a Lingua Materna (LM) quanto a LA nos mais diversos aspectos linguísticos, ao afirmar que o estudante "pondrá a prueba su destreza mediante la traducción continuada de una variedad de material textual real" (PEGENAUTE RODRÍGUEZ, 1996, p. 110). Afirma ainda, que as traduções realizadas poderão ser comparadas com as dos colegas e cada um poderá explicar suas escolhas em detrimento de outras opções de tradução. Baseados nessas reflexões, trabalhamos no projeto de pesquisa, para que, dessa forma, os integrantes do projeto possam aprimorar seus conhecimentos, por meio da discussão das diferentes versões preliminares até chegarem ao Texto Meta Final $\left(\mathrm{TM}_{2}\right)$, sob a orientação dos docentes.

No curso de licenciatura em Letras da referida universidade, são ofertadas disciplinas optativas de tradução, nas quais são realizadas oficinas com diversos materiais a fim de que os alunos percebam diferenças entre as traduções técnica e literária e, desse modo, sintam-se mais preparados, instrumentalizados e aptos para o exercício da tradução literária.

A seleção dos acadêmicos, todos matriculados no curso de licenciatura em Letras Português/Espanhol, foi feita pela análise do seu desempenho ao receberem os insumos, por meio da correção de traduções de pequenos textos literários (fragmentos dos próprios contos da autora) que eram avaliados pelos coordenadores do projeto, para definir o semestre que seria submetido à pesquisa, levando em conta que o tradutor literário deve ter uma sensibilidade que ultrapasse o conhecimento linguístico, considerando a criatividade e a complexidade de seu trabalho. Como o perfil do tradutor literário revela-se na "fidelidade" (TOURY, 2004) ao estilo do autor, ao contexto histórico e sociocultural e na consciência de sua responsabilidade ao recriar a obra literária, foram selecionados alunos do quinto semestre (o curso tem oito semestres ao todo), que ainda não tinham recebido insumos teóricos sobre os Estudos da Tradução.

Quanto ao corpus de análise, os contos selecionados para a tradução foram escolhidos pelos coordenadores, seguindo os critérios de grau de complexidade estilística da autora, período de publicação e temática abordada. Para isso, foram lidos os livros de contos Sueños y realidades (1907) e Panoramas de la vida (1876), que pertencem à primeira fase de escrita da autora e foram selecionados os seguintes contos: "El ángel caído"; "Una apuesta"; "La novia del muerto"; "Caer de las nubes"; "La hija del mashorquero"; "El guante negro"; "Si practicas el mal, no esperes el bien"; "El emparedado"; "El lucero del manantial"; "Yerbas y alfileres"; "Una noche de agonia" e "Un drama en 15 minutos". A análise dos contos detalhou inicialmente elementos textuais (enredo, personagens, tempo e espaço), bem como o contexto socio-histórico, analisando também aspectos de diversos interesses: feminismo, historiografia, sociologia, politica, geografia, entre outros, com a finalidade de aproximar o aprendiz do universo do Texto de Origem (TO). 
Após a leitura e a análise dos contos, os acadêmicos procederam à tradução e, para isso, tiveram livre acesso a todo tipo de dicionários; podiam traduzir em suas casas ou em um espaço reservado a eles dentro da universidade (uma sala com computadores e acesso à internet) e estabeleceu-se um prazo de um mês para que entregassem a tradução. Mediante a aplicação do questionário inicial, as variantes de sexo, idade e nível socioeconômico foram neutralizadas, dado que as tradutoras são todas mulheres, com idades entre 22 e 25 anos e têm o mesmo nível socioeconômico ( $\mathrm{C}$ - Classe média).

Ao finalizarem a tradução, obteve-se o Texto Meta Preliminar $\left(\mathrm{TM}_{1}\right)$, e, logo após, os coordenadores revisaram cada conto, apontando as dificuldades a serem solucionadas e, finalmente, foi elaborado o Texto Meta Final $\left(\mathrm{TM}_{2}\right)$. O estágio atual do projeto consiste na revisão final dos $\mathrm{TM}_{2}$, sob a responsabilidade de toda a equipe, verificando as dificuldades encontradas pelos alunos, tais como o contexto histórico do ambiente dos contos, as metáforas e outras figuras de linguagem, as expressões idiomáticas, o léxico do espanhol do século XIX, o uso de heterossemânticos, as referências mitológicas etc., que serão trabalhados de forma mais aprofundada, posteriormente, em sala de aula, para aperfeiçoar ambos os idiomas. Porém, ao identificar as próprias dificuldades, os alunos já demonstram aumentar a sua competência linguística no par de idiomas estudado, conforme preconizado por Pegenaute Rodríguez (1996).

Com relação ao contexto histórico do século XIX, dados e personagens históricos como Juan Manuel de Rosas, Juan Lavalle, Juan Martín de Pueyrredón, Carlos María de Alvear receberam notas explicativas nas traduções, a fim de aproximar o texto original da Argentina do século XIX do leitor brasileiro do século XXI. Na tradução final, optou-se por manter os nomes próprios dos personagens históricos e dos locais públicos, o que exigiu dos acadêmicos a pesquisa sobre a real existência dos personagens e dos locais mencionados nos contos. Desse modo, os estudantes, futuros tradutores literários, tiveram a oportunidade de aprimorar-se não só em questões gramaticais, mas também conhecer aspectos históricos, políticos, geográficos e sociais da Argentina do século XIX.

Além do perfil do tradutor literário, outros critérios estabelecidos pelos coordenadores do projeto foram observados na atividade tradutória, para que os alunos aumentem sua competência linguística na LM e na LA. São eles:

1. Domínio da LM e da LA, já que a tradução requer um grande conhecimento da lingua adicional que será aperfeiçoada; foram seguidos autores como Leffa (1988) e Hurtado Albir (1999), que afirmam que se deve usar esse tipo de atividade em níveis intermediários e avançados de ensino.

2. Uma lingua materna comum a todo o grupo; no caso do nosso projeto, trata-se de brasileiras que aprendem espanhol em contexto formal de ensino superior no Brasil, fora do contexto de imersão na LA.

3. Um grupo adulto, pois a tradução como ferramenta didática exige certa capacidade de reflexão e certa maturidade intelectual, podendo-se afirmar que esse exercício apresenta um alto nível de raciocínio.

4. O objetivo do curso, pois a competência comunicativa é a finalidade do curso de ensino de LA; embora às vezes haja objetivos específicos como a docência ou a formação do tradutor literário. 
A seguir, serão apresentados alguns exemplos da análise inicial, extraídos dos contos que compõem o projeto, dada a extensão limite deste texto. Para efeitos de organização, os fragmentos foram elencados por dificuldades e neles aparecem diferentes tipos de problemas gramaticais, lexicais e estilísticos. Para este artigo, foram selecionados problemas recorrentes nos diferentes $\mathrm{TM}_{1}$, que foram percebidos e corrigidos pelos aprendizes, gerando os $\mathrm{TM}_{2}$.

Com relação ao Sintagma Nominal, é possivel observar, nos TO, que o adjunto adnominal aparece anteposto ao núcleo, dentro do sintagma nominal, o que, embora permitido, é diferente do estabelecido pela ordem canônica dos dois idiomas ${ }^{2}$, indicando que a autora optou por inverter a ordem tradicional. Em casos como esses, é possivel ver que os aprendizes, nos $\mathrm{TM}_{1}$ mantêm a ordem canônica e, ao perceberem que a inversão se deve a uma opção da autora, reelaboram os $\mathrm{TM}_{2}$ para manter-se fiel na acepção dada por Toury (2004), ao TO, revelando ao leitor final a estilística do texto traduzido.

$\mathrm{TO}^{3} \quad$ [En aquel heterogéneo círculo doblemente alumbrado por el gás y las brasas del hogar.]

$\mathrm{TM}_{1}$ [Naquele círculo heterogêneo duplamente alumbrado pelo gás e pelas brasas do lar.]

$\mathrm{TM}_{2}$ [Naquele heterogêneo círculo duplamente alumbrado pelo gás e pelas brasas do lar.]

$\mathrm{TO}^{4}$ [Silencio solo interrumpido por el prolongado y lamentable canto del coyuyu.]

$\mathrm{TM}_{1}$ [Silêncio só interrompido pelo canto prolongado e lamentável do coyuyu.]

$\mathrm{TM}_{2}$ [Silêncio só interrompido pelo prolongado e lamentável canto do coyuyu.]

$\mathrm{TO}^{5}$ [Al lado de aquel sangriento lecho se hallaba de rodillas una mujer de estatura elevada.]

$\mathrm{TM}_{1}$ [Ao lado daquele leito sangrento encontrava-se de joelhos uma mulher de estatura elevada.]

$\mathrm{TM}_{2}$ [Ao lado daquele sangrento leito encontrava-se de joelhos uma mulher de estatura elevada.]

$\mathrm{TO}^{6}$ [Los habitantes de los vecinos campos se encontraban todavía en las noches del estio.]

$\mathrm{TM}_{1}$ [Os habitantes dos campos vizinhos encontravam-se ainda nas noites de verão.]

$\mathrm{TM}_{2}$ [Os habitantes dos vizinhos campos encontravam-se ainda nas noites de verão.]

\footnotetext{
2 Conforme a Moderna Gramática Portuguesa (BECHARA, 2009) e a Nueva Gramática de la Lengua Española (2010), no que diz respeito ao português e ao espanhol, respectivamente. Cabe destacar que ambas são gramáticas normativas, pois, nas traduções sob análise, buscou-se o uso da norma padrão, tal como preconizado por Toury (2004).

3 "El emparedado"

4 "El lucero del manantial"

5 "El guante negro"

6 "La novia del muerto"
} 
$\mathrm{TO}^{7} \quad$ [Pero la voz alegre de su padre disipó su penosa emoción.]

$\mathrm{TM}_{1} \quad$ [Mas a voz alegre de seu pai dissipou sua emoção penosa.]

$\mathrm{TM}_{2}$ [Mas a voz alegre de seu pai dissipou sua penosa emoção.]

Outra dificuldade encontrada refere-se ao vocativo, no qual a autora argentina mantém a ordem canônica do idioma espanhol, fato que provavelmente se deve ao uso pragmático do vocativo nesse idioma. Ao ver os vocativos nos TO, mantendo a ordem do adjunto adnominal posposto ao núcleo, dentro do sintagma nominal, os aprendizes fizeram o mesmo. Porém, ao entenderem que a autora fez isso para manter a ordem canônica do TO, verificaram como era o uso do vocativo na sua LM e perceberam que pragmaticamente era ao contrário: adjunto adnominal anteposto ao núcleo, dentro do sintagma nominal (BECHARA, 2009). Dessa forma, decidiram realizar os $\mathrm{TM}_{2}$ mantendo a ordem canônica do vocativo na LM para um melhor entendimento do público leitor do texto traduzido, como feito nos TO. Essas ações refletem o amadurecimento do aprendiz tanto na LM como na LA, por meio do uso da tradução como ferramenta de ensino-aprendizado.

$\mathrm{TO}^{8} \quad$ [¿Qué pesar oscurece su frente, amada mia?]

$\mathrm{TM}_{1} \quad$ [Que pesar escurece seu semblante, amada minha?]

$\mathrm{TM}_{2}$ [Que pesar escurece seu semblante, minha amada?]

$\mathrm{TO}^{9} \quad$ [Dios mio, murmuró Vital, ten piedad de mi amor.]

$\mathrm{TM}_{1} \quad$ [Deus meu, murmurou Vital, tenha piedade de meu amor.]

$\mathrm{TM}_{2} \quad$ [Meu Deus, murmurou Vital, tenha piedade de meu amor.]

$\mathrm{TO}^{10}$ [Esta misma adhesión, madre mía, realza más la magnidad de ese corazón generoso.]

$\mathrm{TM}_{1}$ [Esta mesma adesão, mãe minha, realça mais a magnitude desse coração generoso.]

$\mathrm{TM}_{2}$ [Esta mesma adesão, minha mãe, realça mais a magnitude desse coração generoso.]

$\mathrm{TO}^{11}$ [Un cuchillo, hija mía, un cuchillo es más expeditivo.]

$\mathrm{TM}_{1}$ [Uma faca, filha minha, uma faca é mais eficiente.]

$\mathrm{TM}_{2}$ [Uma faca, minha filha, uma faca é mais eficiente.]

Outro aspecto relevante que demonstra o progresso na aprendizagem do aluno dá-se na percepção de que há uma diferença na correlação de tempos verbais, em função de não haver correspondência direta entre todos os tempos de ambos os idiomas. Os exemplos selecionados permitem verificar que, em um primeiro momento, o aprendiz não percebe que deve realizar essa correlação, recorrendo ao uso de locuções verbais no $\mathrm{TM}_{1}$ para traduzir, por exemplo, o pre-

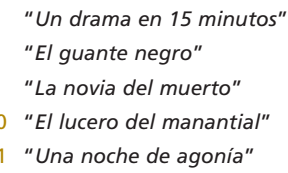


térito perfeito composto do espanhol. Ao perceberem que tanto o pretérito perfeito composto, quanto o pretérito perfeito simples traduzem-se ao português como pretérito perfeito, refizeram o $\mathrm{TM}_{2}$ corretamente.

$\mathrm{TO}^{12}$ [Nada ha cambiado en torno mío.]

$\mathrm{TM}_{1} \quad$ [Nada tem mudado ao meu redor.]

$\mathrm{TM}_{2}$ [Nada mudou ao meu redor.]

$\mathrm{TO}^{13}$ [E1 sol ha sido brillante.]

$\mathrm{TM}_{1} \quad$ [O sol tem sido brilhante.]

$\mathrm{TM}_{2} \quad$ [O sol foi brilhante.]

$\mathrm{TO}^{14}$ [Las flores me han enviado sus más suaves perfumes.]

$\mathrm{TM}_{1} \quad$ [As flores têm me enviado seus mais suaves perfumes.]

$\mathrm{TM}_{2} \quad$ [As flores enviaram-me seus mais suaves perfumes.]

$\mathrm{TO}^{15}$ [Las melodias que han callado.]

$\mathrm{TM}_{1} \quad$ [As melodias que têm calado.]

$\mathrm{TM}_{2} \quad$ [As melodias que calaram.]

Outro aspecto gramatical com o qual foi possivel aferir a melhora do aluno nos dois idiomas diz respeito à análise da regência verbal. Como menciona Cristina Aparecida Duarte (1998), a semelhança entre elementos gramaticais nas línguas espanhola e portuguesa destaca-se como um dos pontos de maior dificuldade. Nesse caso, o estudo da regência verbal diferente nos dois idiomas permitiu que o uso inadequado da preposição não se fossilizasse (GARGALLO, 1993), como é possivel observar nos exemplos a seguir:

$\mathrm{TO}^{16}$ [Los malos pensamientos, hijos de los celos, que convierten al ángel en demônio.]

$\mathrm{TM}_{1}$ [Os maus pensamentos, filhos do ciúmes, que convertem ao anjo em demônio.]

$\mathrm{TM}_{2}$ [Os maus pensamentos, filhos do ciúmes, que convertem o anjo em demônio.]

$\mathrm{TO}^{17}$ [Todo esto con la decisión instantânea y rápida que distingue a los grandes capitanes.]

$\mathrm{TM}_{1}$ [Tudo isto com a decisão instantânea e rápida que distingue aos grandes capitães.]

$\mathrm{TM}_{2}$ [Tudo isto com a decisão instantânea e rápida que distingue os grandes capitães.] 
$\mathrm{TO}^{18}$ [¡Y estrechó en un solo abrazo a los dos amantes!]

$\mathrm{TM}_{1} \quad$ [E apertou em um só abraço aos dois amantes!]

$\mathrm{TM}_{2}$ [E apertou em um só abraço os dois amantes!]

$\mathrm{TO}^{19}$ [Su presencia intimidaba a las chicas y las impedia entregarse a los compases de Strauss.]

$\mathrm{TM}_{1}$ [Sua presença intimidava às meninas e as impedia entregar-se aos compassos de Strauss.]

$\mathrm{TM}_{2}$ [Sua presença intimidava as meninas e as impedia de entregar-se aos compassos de Strauss.]

$\mathrm{TO}^{20}$ [Y con la mirada y el oído atento, interrogaba angustiosamente a la noche y al silencio.]

$\mathrm{TM}_{1} \quad[\mathrm{E}$ com o olhar e o ouvido atento, interrogava angustiosamente à noite e ao silêncio.]

$\mathrm{TM}_{2}$ [E com o olhar e o ouvido atento, interrogava angustiosamente a noite e o silêncio.]

Outro problema gramatical superado com a atividade tradutória em sala de aula foi o uso da colocação pronominal em ambos os idiomas. Como em espanhol os verbos conjugados recebem os pronomes na posição de próclise - conforme a Nueva Gramática de la Lengua Española (2010) -, nos TM 1 os pronomes aparecem nessa mesma posição. Ao estudar o uso da colocação pronominal em português e verificar que esse uso proclítico acontece na linguagem coloquial conforme Silva (2000) - e perceber que na linguagem escrita formal usa-se a ênclise - conforme Evanildo Bechara (2009) -, excetuando os casos em que os pronomes são atraídos por outra partícula e devem assumir a posição de próclise, os $\mathrm{TM}_{2}$ foram modificados, demonstrando esse aprendizado.

$\mathrm{TO}^{21}$ [Su voz se extinguió en un suspiro.]

$\mathrm{TM}_{1} \quad$ [Sua voz se extinguiu em um suspiro.]

$\mathrm{TM}_{2}$ [Sua voz extinguiu-se em um suspiro.]

$\mathrm{TO}^{22}$ [Y se le condene al relato de una coincidencia.]

$\mathrm{TM}_{1} \quad$ [E o condene ao relato de uma coincidência.]

$\mathrm{TM}_{2}$ [E condene-o ao relato de uma coincidência.]

$\mathrm{TO}^{23}$ [El portero que velaba en la primera antesala se inclinó profundamente.]

$\mathrm{TM}_{1}$ [O porteiro que velava na primeira antessala se inclinou profundamente.]

$\mathrm{TM}_{2}$ [O porteiro que velava na primeira antessala inclinou-se profundamente.]

18 "Un drama en 15 minutos"

19 "El emparedado"

20 "La hija del mashorquero"

21 "Yerbas $y$ alfileres"

22 "El emparedado"

23 "El guante negro" 
DOSSIE

$\mathrm{TO}^{24}$ [Se encuentra en el capítulo octavo de las Confesiones de San Agustín.]

$\mathrm{TM}_{1}$ [Se encontra no capítulo oitavo das Confissões de Santo Agostinho.]

$\mathrm{TM}_{2}$ [Encontra-se no capítulo oitavo das Confissões de Santo Agostinho.]

Além dos problemas gramaticais, o léxico também oferece grandes obstáculo para realizar uma tradução. Geralmente, quando os alunos não sabem o significado de uma palavra, buscam-no no dicionário, mas o problema reside no fato de olharem, em geral, apenas a primeira acepção da palavra. No entanto, quase sempre, há mais de uma e os alunos não percebem que, em determinados contextos, a primeira acepção não está correta. A seguir, mostram-se exemplos nos quais é possivel perceber a melhora dos alunos, ao aprenderem a selecionar o léxico mais apropriado para determinado contexto.

$\mathrm{TO}^{25}$ [No he pensado aún en curar tu herida.]

$\mathrm{TM}_{1}$ [Não pensei ainda em curar tua ferida.]

$\mathrm{TM}_{2}$ [Não pensei ainda em tratar tua ferida.]

$\mathrm{TO}^{26}$ [Imprimió en ella un beso.]

$\mathrm{TM}_{1} \quad$ [Imprimiu nela um beijo.]

$\mathrm{TM}_{2}$ [Deu-lhe um beijo.]

$\mathrm{TO}^{27}$ [El rostro bronceado y grave de Bracho.]

$\mathrm{TM}_{1}$ [O rosto bronzeado e grave de Bracho.]

$\mathrm{TM}_{2}$ [O rosto bronzeado e sério de Bracho.]

$\mathrm{TO}^{28}$ [Un terrible recuerdo brilló como un relámpago en la memoria de Wenceslau, que llevó vivamente las manos al pecho.]

$\mathrm{TM}_{1}$ [Uma terrivel lembrança brilhou como um relâmpago na memória de Wenceslau, que levou vivamente as mãos ao peito.]

$\mathrm{TM}_{2}$ [Uma terrivel lembrança brilhou como um relâmpago na memória de Wenceslau, que levou rapidamente as mãos ao peito.]

No primeiro exemplo a seguir, é possivel perceber que a palavra "grave" foi traduzida por "grave", no entanto, ao analisar o contexto da oração na qual aparece essa palavra, seria mais apropriado traduzir por "sério", dado que tal vocábulo é polissêmico e, no exemplo, está sendo usado no seu "significado figurado" (NEWMARK, 2010 [1992]). Já no exemplo posterior, é possivel perceber que o aprendiz realizou uma tradução correta já na primeira versão, já que o contexto demonstra a relação com o som, pois se refere ao som do eco, ou seja, a palavra está usada no "significado físico" (NEWMARK, 2010 [1992]).

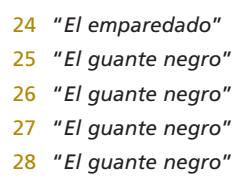


$\mathrm{TO}^{29}$ [E1 otro niño respondió con acento grave y resignado.]

$\mathrm{TM}_{1} \quad$ [O outro menino respondeu com sotaque grave e resignado.]

$\mathrm{TM}_{2} \quad$ [O outro menino respondeu com tom sério e resignado.]

$\mathrm{TO}^{30}$ [La hechicera sevillana entró ... despertando los graves ecos.]

$\mathrm{TM}_{1}=\mathrm{TM}_{2} \quad$ [A feiticeira sevilhana entrou ... despertando os graves ecos. $]$

Ao analisar os $\mathrm{TM}_{1}$ e $\mathrm{TM}_{2}$, no que diz respeito às expressões idiomáticas - "lexia complexa indecomponivel, conotativa e cristalizada em um idioma pela tradição cultural" (XATARA, 2001, p. 51) - que aparecem nos TO, é possivel verificar que o aprendiz teve dificuldades em compreender a expressão idiomática na LA, ao buscar o significado literal, o sentido denotativo. Porém, ao utilizar uma segunda estratégia metacognitiva, mostrou-se capaz de elaborar o significado da sequência de palavras em seu contexto e não do vocábulo isolado, percebendo, assim, o sentido conotativo, traduzindo com êxito a expressão para a LM, como se pode observar nos exemplos a seguir:

$\mathrm{TO}^{31}$ [La verdad toda entera se mostro a sus ojos.]

$\mathrm{TM}_{1} \quad$ [A verdade completa mostrou-se a seus olhos.]

$\mathrm{TM}_{2} \quad$ [A verdade nua e crua mostrou-se a seus olhos.]

$\mathrm{TO}^{32}$ [El tiempo estaba representado en su más lata acción.]

$\mathrm{TM}_{1} \quad$ [O tempo estava representado em seu mais pesado dia.]

$\mathrm{TM}_{2} \quad$ [O tempo estava representado em seu dia mais cinzento.]

$\mathrm{TO}^{33}$ [Como prenda de amistad, respondió ella, alzando con graciosa coquetería la extremidad de su velo.]

$\mathrm{TM}_{1}$ [Como prenda de amizade, respondeu ela, levantando com graciosa sedução a extremidade do seu véu.]

$\mathrm{TM}_{2}$ [Como prova de amizade, respondeu ela, levantando com graciosa sedução a extremidade do seu véu.]

$\mathrm{TO}^{34}$ [Y es fama que nunca quiso casarse por no tener que sonreír... siquiera el día de la boda.]

$\mathrm{TM}_{1} \quad[\mathrm{E}$ é fama que nunca quis casar-se por não ter que sorrir... sequer no dia do casamento.]

$\mathrm{TM}_{2} \quad[\mathrm{E}$ sabe-se que nunca quis casar-se por não ter que sorrir... sequer no dia do casamento.]

Com base na revisão dos $\mathrm{TM}_{2}$, comprovamos o amadurecimento intelectual dos graduandos como tradutores literários em formação, pois tal atividade con-

\footnotetext{
29 "La hija del mashorquero"

30 "Una apuesta"

31 "La hija del mashorquero"

32 "El emparedado"

33 "El guante negro"

34 "Una apuesta"
} 
tribuiu para o aprimoramento da sua competência na LA. Atividades como a descrita neste artigo permitem que o acadêmico amplie seus horizontes culturais, aperfeiçoando não somente a Lingua Adicional, mas também a cultura da Argentina e de outros países citados nos contos, que permitem ao tradutor fazer, por exemplo, inferências sobre situações presentes no texto original, para poder traduzi-las de modo adequado e coerente.

O projeto de pesquisa encontra-se em fase final, na etapa de revisão linguística, com vistas à publicação da primeira antologia de contos de Juana Manuela Gorriti em língua portuguesa, inteiramente traduzida pelos alunos que participaram do projeto.

Os resultados obtidos reafirmam que a implementação da atividade de tradução literária é eficaz para o crescimento profissional, pessoal e cultural dos agentes envolvidos no processo, pois instrumentaliza os acadêmicos de Letras para que sejam professores competentes e, também, sensiveis tradutores literários.

\title{
The translation of Juana Manuela Gorriti tales into Brazilian Portuguese
}

\begin{abstract}
This paper aims to share the results of the research project "Juana Manuela Gorriti: analysis and translation". Developed by graduate students of the Portuguese/Spanish Language at Universidade Federal do Rio Grande, such a project is aimed at translating Juana Manuela Gorriti's literary work into Brazilian Portuguese, as well as improving the knowledge of Spanish language students involved in it. The analysis is based on Gideon Toury's Descriptive Translation Studies (2004), which proposes pre-established norms to be used in the translation act.
\end{abstract}

Keywords: Descriptive translation studies. Literary translation. Juana Manuela Gorriti.

\section{REFERÊNCIAS}

ARROJO, R. Os estudos da tradução na pós-modernidade, o reconhecimento da diferença e a perda da inocência. Cadernos de Tradução, Florianópolis, v. 1, p. 53-69, 1996. Disponível em: <https://periodicos.ufsc.br/index.php/traducao/article/view/5064>. Acesso em: 10 ago. 2017.

BECHARA, E. Moderna gramática portuguesa. São Paulo: Nova Fronteira, 2009. DUARTE, C. A. Reflexiones sobre la enseñanza de las preposiciones españolas brasileños. In: CONGRESO INTERNACIONAL DE LA ASELE - Español como Lengua Extranjera: Enfoque Comunicativo y Gramática, 9., 1998, Santiago de Compostela. Santiago de Compostelo: La Asele, 1998.

GARGALLO, I. S. Análisis contrastivo, análisis de errores e interlengua, en el marco de la Lingüística Contrastiva. Madrid: Sintesis, 1993.

GORRITI, J. M. Panoramas de la vida: colección de novelas, fantasías, leyendas y descripciones americanas. Buenos Aires: Imprenta y Librarías de Mayo, 1876. GORRITI, J. M. Sueños y realidades. Buenos Aires: La Nación, 1907. 2 v. 
GORRITI, J. M. Dreams and realities. Tradução Sérgio Waisman. New York: Oxford University, 2003. Disponivel em: <books.google.com.br/ books?id=UssVK2HOU4Wc>. Acesso em: 10 set. 2017.

HURTADO ALBIR, A. Enseñar a traducir. metodología na formação de tradutores e intérpretes. Madrid: Edelsa, 1999.

HURTADO ALBIR, A. Traducción y traductología. Introdução a tradutología. 6. ed. Madrid: Cátedra, 2013.

LEFEVERE, A. Why waste our time on rewrites? The trouble of interpretation and the role of rewriting in an alternative paradigm. In: HERMANS, T. (Ed.). The manipulation of literature: studies in literary translation. London: Croom Helm, 1985. p. 215-243.

LEFEVERE, A. Traducción, reescritura y la manipulación del canon literario. Salamanca: Ediciones Colegio de España, 1997.

LEFFA, V. J. Metodologia do ensino de linguas. In: BOHN, H. I.; VANDRESEN, P. Tópicos em lingüística aplicada: o ensino de línguas estrangeiras. Florianópolis: Ed. da UFSC, 1988.

LEFFA, V. J.; IRALA, V. B. (Org.). Uma espiadinha na sala de aula. Pelotas: Educat, 2014.

NEWMARK, P. Manual de traducción. Madrid: Cátedra, 2010.

PEGENAUTE RODRÍGUEZ, L. La traducción como herramienta didáctica. Contextos, Madrid, n. 27-28, p. 107-126, 1996.

REAL ACADEMIA ESPAÑOLA; ASOCIACIÓN DE ACADEMIAS DE LA LENGUA ESPAÑOLA. Nueva Gramática de la Lengua Española. Manual. Buenos Aires: Espasa, 2010.

SILVA, M. A. M. A variação da colocação pronominal do português culto do Brasil. 2000. Dissertação (Mestrado em Letras)-Instituto de Letras, Universidade Federal Fluminense, Niterói, 2000.

TOURY, G. In search of a Theory of Translation. Tel Aviv: Tel Aviv University, 1980.

TOURY, G. Descriptive translation studies and beyond. Amsterdam: John Benjamins, 1995.

TOURY, G. Los estudios descriptivos de traducción y más allá. Metodología da investigação em estudos de tradução. Madrid: Cátedra, 2004.

XATARA, C. M. O ensino do léxico: as expressões idiomáticas. Trabalhos em Linguistica Aplicada, v. 37, p. 49-59, 2001.

Recebido em agosto de 2017. Aprovado em setembro de 2017. 